\title{
Flexible Organic Light-Emitting Diodes Encapsulated with Gas Barrier Films Prepared by Atomic Layer Deposition
}

\author{
Fa-Ta Tsai, Ching-Kong Chao, Pei-Sin Jhu, ${ }^{1}$ and Rwei-Ching Chang ${ }^{1 *}$ \\ Department of Mechanical Engineering, National Taiwan University of Science and Technology, \\ 43, Keelung Rd. Sec.4, Taipei City 10607, Taiwan \\ ${ }^{1}$ Department of Mechanical and Computer-Aided Engineering, St. John's University, \\ 499, Tamking Rd. Sec. 4, Tamsui, New Taipei City 25135, Taiwan
}

(Received December 22, 2015; accepted May 20, 2016)

Keywords: atomic layer deposition, flexible OLED, encapsulation, gas barrier film

Various encapsulating films for flexible organic light-emitting diodes (OLEDs) were studied, and gas barrier layers including inorganic $\mathrm{Al}_{2} \mathrm{O}_{3}$ thin films prepared by atomic layer deposition, organic Parylene $\mathrm{C}$ thin films prepared by chemical vapor deposition, and their combination were considered. The transmittance and water vapor transmission rate (WVTR) of the encapsulating films were tested. The effects of various encapsulating films on the luminance and current density of the OLEDs were compared. Lifetime experiments on OLEDs with these encapsulating films were also conducted. The results showed that the transmittance is acceptable even if the polyethylene terephthalate (PET) substrates were coated with two $\mathrm{Al}_{2} \mathrm{O}_{3}$ and Parylene $\mathrm{C}$ layers. The results also indicated the WVTR of the PET substrate was improved by coating the barrier layers. Evaluation of the performance after encapsulation indicates that the OLEDs with $\mathrm{Al}_{2} \mathrm{O}_{3} / \mathrm{PET}$, Parylene $\mathrm{C} / \mathrm{Al}_{2} \mathrm{O}_{3} /$ PET (1 pair/PET), and Parylene $\mathrm{C} / \mathrm{Al}_{2} \mathrm{O}_{3} /$ Parylene $\mathrm{C} / \mathrm{Al}_{2} \mathrm{O}_{3} /$ PET (2 pairs/PET) presented similarly higher luminance compared with the other two cases. Although the 1 pair/PET encapsulation behaved slightly better in terms of luminance than the 2 pair/PET encapsulation, the 2 pairs/PET encapsulation has much longer lifetime. The OLED with 2 pairs/PET encapsulation had nearly double the lifetime compared with the 1 pair encapsulation, and four times compared with the OLED without encapsulation.

\section{Introduction}

Due to their simplicity, organic light-emitting diodes (OLEDs) can be easily built not only on glass substrates but also on flexible substrates. However, the short lifetimes and low efficiencies of flexible OLEDs are still the major problem to be solved. The problem arises from the penetration of oxygen and water vapor to the organic layers through the substrate and the encapsulated film. ${ }^{(1-3)}$

The basic encapsulation method uses glass and epoxy adhesive in a $\mathrm{N}_{2}$-filled glove box.(4,5) However, glass is not suitable for flexible encapsulation because of its rigid nature. Polymer substrates are the most promising candidates for flexible encapsulation. The water vapor transmission rate (WVTR) of polymer substrates is substantially below the behavior required for OLED encapsulation. Therefore, polymer substrate-coated barrier thin films to improve the WVTR are essential for flexible OLED encapsulation. Carcia et al.(6) used quantitative Ca tests "Corresponding author: e-mail: rcc@mail.sju.edu.tw 
to determine WVTR through $25 \mathrm{~nm}$ thick $\mathrm{Al}_{2} \mathrm{O}_{3}$ gas diffusion barriers grown on plastic by atomic layer deposition (ALD). They concluded that the $\mathrm{Al}_{2} \mathrm{O}_{3}$ gas diffusion barriers grown by ALD can effectively improve the WVTR of the polymers. Mandlik et al. ${ }^{(7)}$ reported that the lifetime of OLEDs encapsulated with part-SiO ${ }_{2}$ part-silicone barrier layers exceeded the industrial requirement by a considerable amount.

Inorganic thin films have shown the potential to be barrier layers for flexible OLED encapsulation. ${ }^{(8)}$ Although these inorganic thin films have low WVTR, pinhole defects cannot be avoided because of limitations of the vacuum deposition process. An organic-inorganic multibarrier became an alternative to prevent the defects. Recently, Han et al. ${ }^{(9)}$ and Kim et al. ${ }^{(10)}$ successfully applied a multibarrier containing organic-inorganic hybrid nanocomposite to thin-film encapsulation of OLEDs. They reported the thin-film encapsulated OLEDs operated stably over $700 \mathrm{~h}$ under ambient conditions. In addition, Singh et al.(11) demonstrated a highly efficient nanolaminate diffusion barrier made of $\mathrm{TiO}_{2} / \mathrm{Al}_{2} \mathrm{O}_{3}$ multilayers using low temperature atomic layer deposition optimized for OLEDs. They found the OLEDs encapsulated with such diffusion barriers displayed few dark spots over $2000 \mathrm{~h}$ of observation after deposition and for aging under ambient conditions. Yang et al. ${ }^{(12)}$ reported a low-temperature thin film encapsulation using an $\mathrm{O}_{3}$-based $\mathrm{ALD}-\mathrm{Al}_{2} \mathrm{O}_{3}$ growth process. They reported that the resultant films exhibited lower surface roughness values, lower WVTR, and longer continuous operating lifetimes. Klumbies et al. ${ }^{(13)}$ investigated the effect of the thickness of ALD-processed $\mathrm{Al}_{2} \mathrm{O}_{3}$ permeation barriers. They found the performance of the thin $\mathrm{Al}_{2} \mathrm{O}_{3}$ permeation barrier was dominated by its defect density.

The organic parylene thin film has been developed and widely commercialized for the capsulation of biomedical implantable devices. Zeniieh et al. ${ }^{(14)}$ used Parylene C multilayer coatings to encapsulate medical implants and implantable bio-transducers. Xie et al. ${ }^{(15)}$ presented an encapsulation scheme that combined ALD $\mathrm{Al}_{2} \mathrm{O}_{3}$ and Parylene $\mathrm{C}$ for the encapsulation of implantable devices. They found the stability of impedance indicated almost no degradation of the encapsulation. These studies indicated that the Parylene $\mathrm{C}$ coatings or the alumina-Parylene coatings were promising candidates for thin film encapsulation.

In this work, to prevent the penetration of water vapor into the OLEDs, various encapsulating films for flexible OLEDs were studied, where gas barrier layers including inorganic $\mathrm{Al}_{2} \mathrm{O}_{3}$ thin films prepared by ALD, organic Parylene $\mathrm{C}$ thin films prepared by chemical vapor deposition, and their combination were evaluated. The transmittance and WVTR of the encapsulating films were tested. The effects of various encapsulating films on the luminance and current density of the OLEDs were compared. Lifetime experiments of the OLEDs with these encapsulating films were also conducted.

\section{Specimen Preparation}

A sketch of an OLED is shown in Fig. 1, where an ITO anode, a PEDOT:PSS (Clevios AI4083) hole injecting layer (HIL), a N,N'-diphenyl-N,N'-bis(1-naphthyl)-1,1'-biphenyl-4,4"-diamine (NPB) hole transporting layer (HTL), a tris-(8-hydroxyquinolinato) aluminum ( $\left.\mathrm{Alq}_{3}\right)$ emitting layer (EL), an aluminum cathode, and a PET cover were stacked in sequence on a PET flexible substrate. Before deposition, the $300 \times 200 \times 0.175 \mathrm{~mm}^{3}$ ITO-coated PET substrate was treated with a standard cleaning procedure including an ultrasonic bath and oxygen plasma. To fabricate the OLED, a PEDOT:PSS film was deposited on the ITO/PET substrate by spin coating. The specimen was dried at $70{ }^{\circ} \mathrm{C}$ for $10 \mathrm{~min}$. Then, the NPB HTL and $\mathrm{Alq}_{3} \mathrm{EL}$ were deposited by thermal evaporation with $1 \AA / \mathrm{s}$ deposition rate. A 200-nm-thick Al cathode was evaporated next. Finally, 


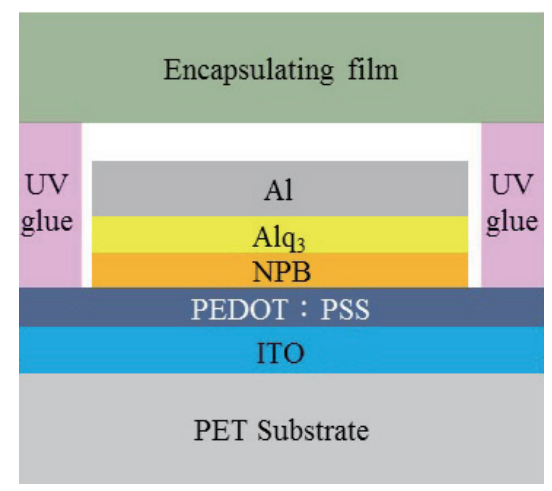

Fig. 1. (Color online) Sketch of a flexible OLED.

the device was covered with various encapsulating films and packaged with UV glue and UV light curing for $1 \mathrm{~h}$.

To prepare the encapsulating films, $\mathrm{Al}_{2} \mathrm{O}_{3}$ thin films were fabricated on PET substrates by ALD. Controlled by the ALD reactor, the precursor and purging gas flow passed the substrate surface uniformly, where the substrate temperature and the chamber pressure were controlled at $60{ }^{\circ} \mathrm{C}$ and $9 \times 10^{-3}$ Torr. The precursor $\mathrm{H}_{2} \mathrm{O}$, purging $\mathrm{N}_{2}$ gas, precursor trimethyl aluminum (TMA), and purging $\mathrm{N}_{2}$ gas flowed into the chamber in sequence. The $\mathrm{Al}_{2} \mathrm{O}_{3}$ film grew sequentially with 10 msec precursor $\mathrm{H}_{2} \mathrm{O}, 6000 \mathrm{~ms} \mathrm{~N}_{2}$ purging, $10 \mathrm{msec}$ precursor TMA, and $6000 \mathrm{~ms} \mathrm{~N}_{2}$ purging. The film thickness was controlled at $50 \mathrm{~nm}$, for which nearly 500 cycles were needed.

Parylene C thin films 100-nm thick were deposited by a chemical vapor deposition system. Parylene $\mathrm{C}$ powders were evaporated at $150{ }^{\circ} \mathrm{C}$ and pyrolyzed at $650{ }^{\circ} \mathrm{C}$. The deposition temperature was room temperature and the deposition time was $1 \mathrm{~h}$.

In this work, five encapsulation types were considered, including no encapsulation, $\mathrm{PET}, \mathrm{Al}_{2} \mathrm{O}_{3} /$ PET, Parylene $\mathrm{C} / \mathrm{Al}_{2} \mathrm{O}_{3} /$ PET, and Parylene $\mathrm{C} / \mathrm{Al}_{2} \mathrm{O}_{3} /$ Parylene $\mathrm{C} / \mathrm{Al}_{2} \mathrm{O}_{3} /$ PET. In the following discussion, the fourth and fifth types are simply denoted as 1 pair/PET and 2 pairs/PET.

\section{Results and Discussion}

Using atomic force microscopy (AFM), surface images of the encapsulating films were collected and are shown in Fig. 2. The images show that the surface roughness improves after coating the $\mathrm{Al}_{2} \mathrm{O}_{3}$ encapsulating film by ALD, but the roughness increases after coating the Parylene $\mathrm{C}$ film. Figure 2(a) shows an image of the smooth surface of a PET substrate without any encapsulating film. Figure 2(b) shows the image of the surface of the PET substrate coated by $50 \mathrm{~nm} \mathrm{Al}_{2} \mathrm{O}_{3}$ film deposited by ALD. Figure 2(c) shows the AFM image of the PET coated by the hybrid encapsulating films consisting of Parylene $\mathrm{C}$ and $\mathrm{Al}_{2} \mathrm{O}_{3}$. Figure 2(d) shows the $\mathrm{AFM}$ image of the PET coated by 2 pairs of the hybrid encapsulating films consisting of Parylene $\mathrm{C} / \mathrm{Al}_{2} \mathrm{O}_{3} /$ Parylene $\mathrm{C} /$ $\mathrm{Al}_{2} \mathrm{O}_{3}$. The average roughness in each case is listed in Table 1. It indicates that the roughness of the bare PET substrate was $1.46 \mathrm{~nm}$, and that it decreased to $1.25 \mathrm{~nm}$ after coating with the $\mathrm{Al}_{2} \mathrm{O}_{3}$ encapsulating film. The roughness of the PET substrate coated by the 1 pair encapsulating film was $4.23 \mathrm{~nm}$, which then increased to $5.35 \mathrm{~nm}$ when the PET was coated by 2 pairs of the encapsulating films. 


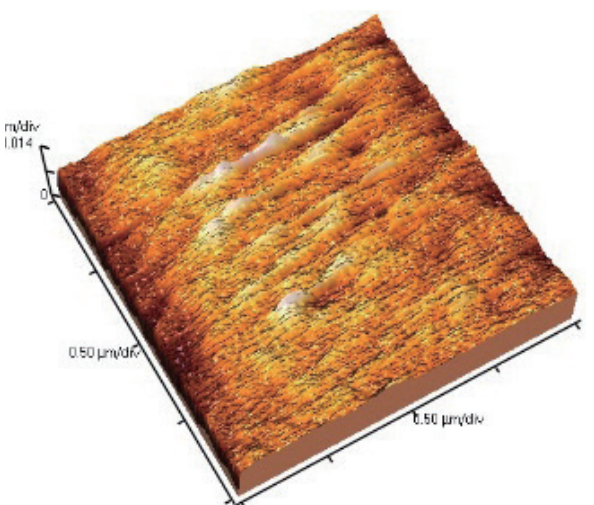

(a)

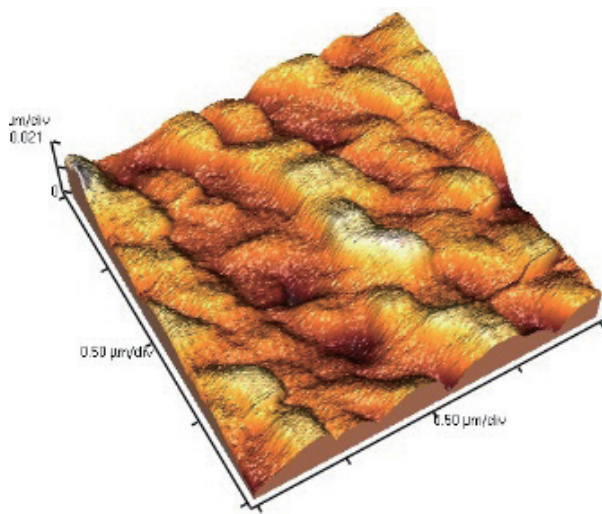

(c)

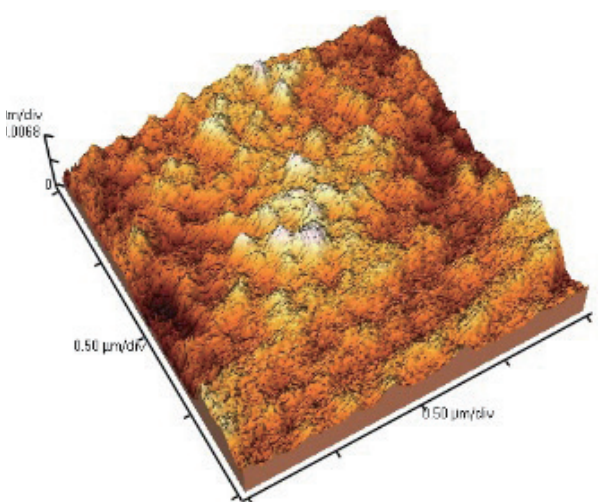

(b)

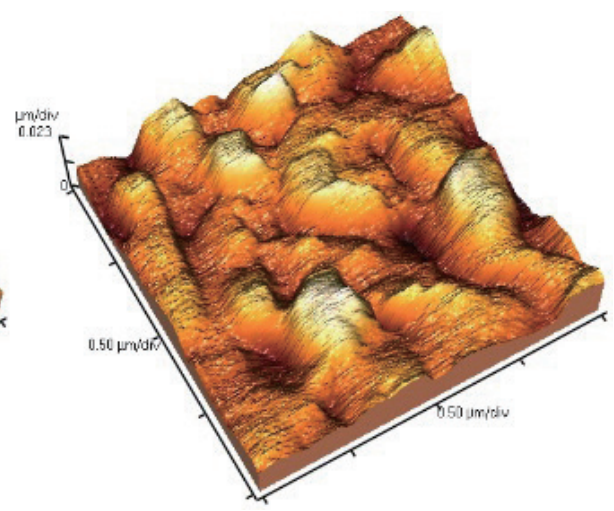

(d)

Fig. 2. (Color online) AFM surface images of the encapsulating films. (a) PET, (b) $\mathrm{Al}_{2} \mathrm{O}_{3} / \mathrm{PET}$, (c) 1 pair/PET, and (d) 2 pairs/PET.

Table 1

Roughness of the encapsulated films.

\begin{tabular}{lcc}
\hline Type & Encapsulating films & Roughness $R a(\mathrm{~nm})$ \\
\hline PET & PET & $1.46 \pm 0.41$ \\
$\mathrm{Al}_{2} \mathrm{O}_{3} /$ PET & $\mathrm{Al}_{2} \mathrm{O}_{3} /$ PET & $1.25 \pm 0.91$ \\
1 pair/PET & Parylene C/Al $\mathrm{O}_{3} /$ PET & $4.23 \pm 1.55$ \\
2 pairs/PET & Parylene $\mathrm{C} / \mathrm{Al}_{2} \mathrm{O}_{3} /$ Parylene $/ \mathrm{Al}_{2} \mathrm{O}_{3} /$ PET & $5.35 \pm 2.23$ \\
\hline
\end{tabular}

Optical transmittance of the encapsulating films was measured using an UV/VIS/NIR spectrophotometer (BWTEK BTC112) with normal incidence in the visible wavelength ranging from 400 to $800 \mathrm{~nm}$, taking air as reference. The results are shown in Fig. 3, where the average transmittance of the PET substrate is $88.16 \%$, PET coated $\mathrm{Al}_{2} \mathrm{O}_{3}$ is $87.05 \%, 1$ pair/PET is $86.56 \%$, and 2 pairs/PET is $84.65 \%$. Obviously, the transmittance decreases as the number of barrier layers increases. However, there is only $1-5 \%$ transmittance loss due to the addition of the barrier layers. 
The WVTR of the encapsulating films is shown in Fig. 4. The figure shows the average WVTR of PET is $11.08 \mathrm{~g} / \mathrm{m}^{2}$ day, where $\mathrm{Al}_{2} \mathrm{O}_{3} /$ PET is $3.44 \mathrm{~g} / \mathrm{m}^{2} \cdot$ day, 1 pair/PET is $3.36 \mathrm{~g} / \mathrm{m}^{2} \cdot$ day, and 2 pairs $/$ PET is $2.77 \mathrm{~g} / \mathrm{m}^{2}$ day. The results indicate that 2 pairs $/$ PET had the best water and vapor barrier performance, which was 4 times better than the bare PET. The data also reveal that the PET substrate coated with a barrier layer efficiently improved the water-vapor resistance. The day-byday results of the WVTR of each encapsulating film are listed in Table 2.

The luminance of the OLEDs with various encapsulating films is shown in Fig. 5. The results show that the OLEDs worked for applied voltages higher than $3 \mathrm{~V}$, and that the luminance increased rapidly as the voltage was increased. The data show that the luminance of the OLED without the encapsulating film is $111.82 \mathrm{~cd} / \mathrm{m}^{2}$ at $8 \mathrm{~V}$, and that the luminances of OLEDs with PET, $\mathrm{Al}_{2} \mathrm{O}_{3} / \mathrm{PET}$, 1 pair/PET, and 2 pairs/PET are $162.18,540.58,557.23$, and $544.93 \mathrm{~cd} / \mathrm{m}^{2}$ at $8 \mathrm{~V}$, respectively.

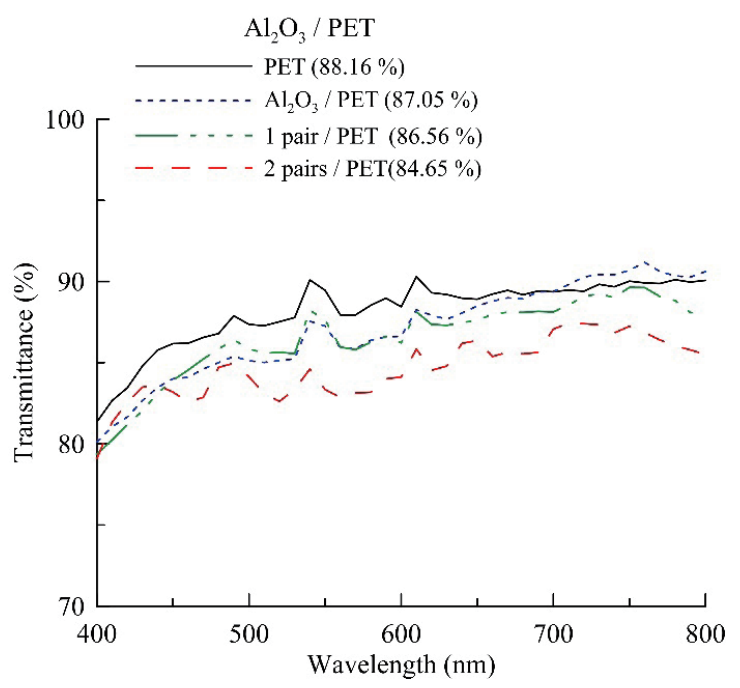

Fig. 3. (Color online) Transmittance of the encapsulating films.

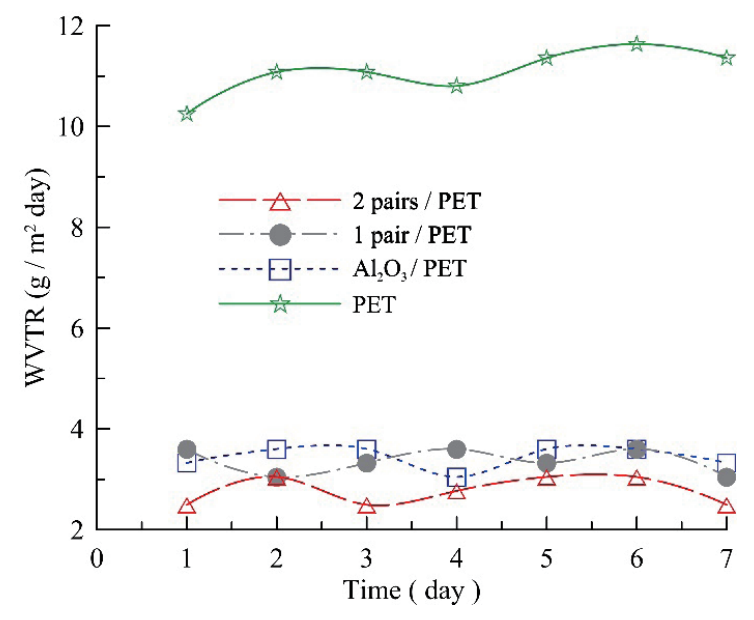

Fig. 4. (Color online) WVTR of the encapsulating films.

Table 2

(Color online) WVTR of the encapsulating films (unit: $\mathrm{g} / \mathrm{m}^{2} \cdot$ day).

\begin{tabular}{|c|c|c|c|c|}
\hline \multirow[b]{5}{*}{ Day } & & & \multirow[b]{3}{*}{ Parylene C } & \multirow{2}{*}{$\begin{array}{c}\text { Parylene C } \\
\qquad \mathrm{Al}_{2} \mathrm{O}_{3}\end{array}$} \\
\hline & & & & \\
\hline & & & & Parylene C \\
\hline & & $\mathrm{Al}_{2} \mathrm{O}_{3}$ & $\mathrm{Al}_{2} \mathrm{O}_{3}$ & $\mathrm{Al}_{2} \mathrm{O}_{3}$ \\
\hline & PET & PET & PET & PET \\
\hline 1 & 10.2485 & 3.3239 & 3.6008 & 2.4929 \\
\hline 2 & 11.0795 & 3.6008 & 3.0469 & 3.0469 \\
\hline 3 & 11.0795 & 3.6008 & 3.3239 & 2.4929 \\
\hline 4 & 10.8025 & 3.0469 & 3.6008 & 2.7699 \\
\hline 5 & 11.3565 & 3.6008 & 3.3239 & 3.0469 \\
\hline 6 & 11.6335 & 3.6008 & 3.6008 & 3.0469 \\
\hline 7 & 11.3565 & 3.3239 & 3.0469 & 2.4929 \\
\hline Average & 11.0795 & 3.4426 & 3.3634 & 2.7699 \\
\hline Error & \pm 0.83 & \pm 0.40 & \pm 0.32 & \pm 0.28 \\
\hline
\end{tabular}


This result indicates the OLEDs with $\mathrm{Al}_{2} \mathrm{O}_{3} / \mathrm{PET}, 1$ pair/PET, and 2 pairs/PET presented higher luminance than the other two cases. This observation is consistent with the results for WVTR shown in Fig. 4, revealing that the barrier performance of bare PET is as poor as having no encapsulating film.

The current density vs voltage diagram of the OLEDs with various encapsulating films is shown in Fig. 6, which is similar to the luminance diagram shown in Fig. 5. The luminance and corresponding images of OLEDs with various encapsulating films at $8 \mathrm{~V}$ are listed in Table 3. Each luminant area of the OLED is $2 \times 2 \mathrm{~mm}^{2}$. The images indicate that OLEDs without encapsulation or with bare PET encapsulation have many black points, and that the OLED with 2 pairs/PET encapsulation has the best emitting patterns.

The lifetime of OLEDs with various encapsulating films is shown in Fig. 7. The lifetime of the OLED is indicated by the normalized luminance $\left(L / L_{0}\right)$ as shown by the ratio of the luminanceafter-usage hours $(L)$ to the luminance-at-begin $\left(L_{0}\right)$. For the OLED without encapsulation, the

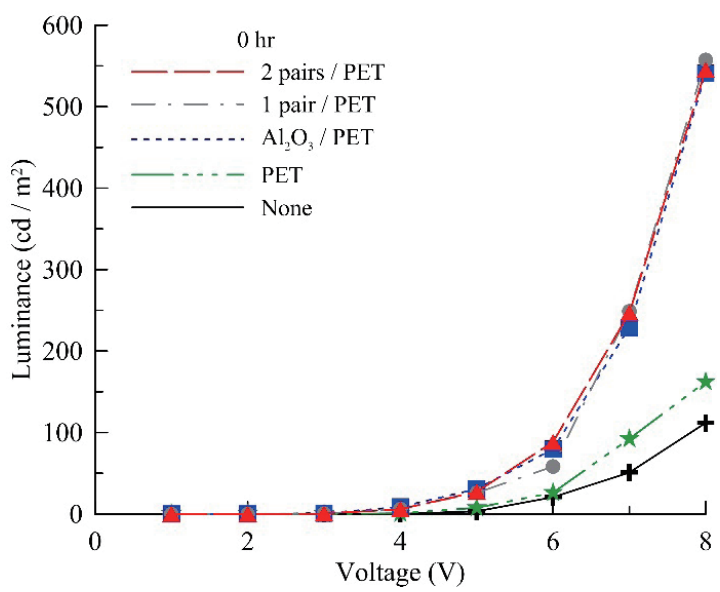

Fig. 5. (Color online) Luminance of OLEDs with various encapsulating films.

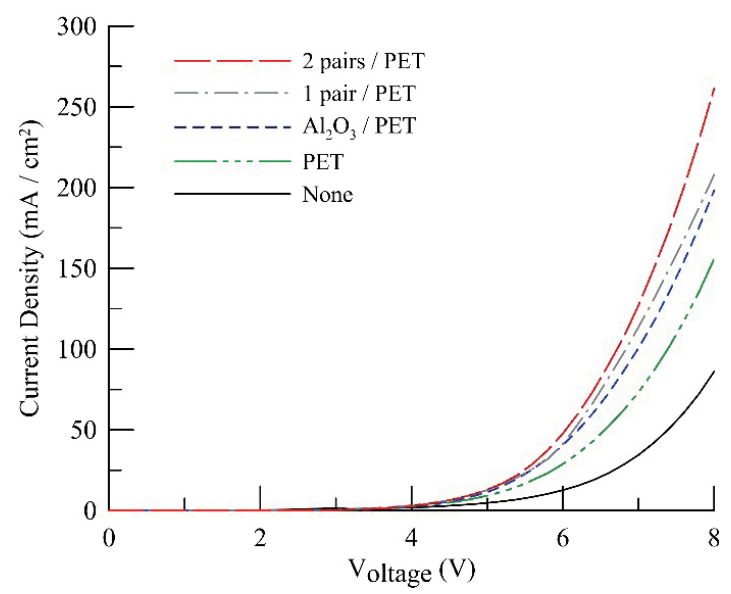

Fig. 6. (Color online) Current density vs voltage diagram of OLEDs with various encapsulating films.

Table 3

(Color online) Luminance and corresponding images of OLEDs with various encapsulated films at $8 \mathrm{~V}$.

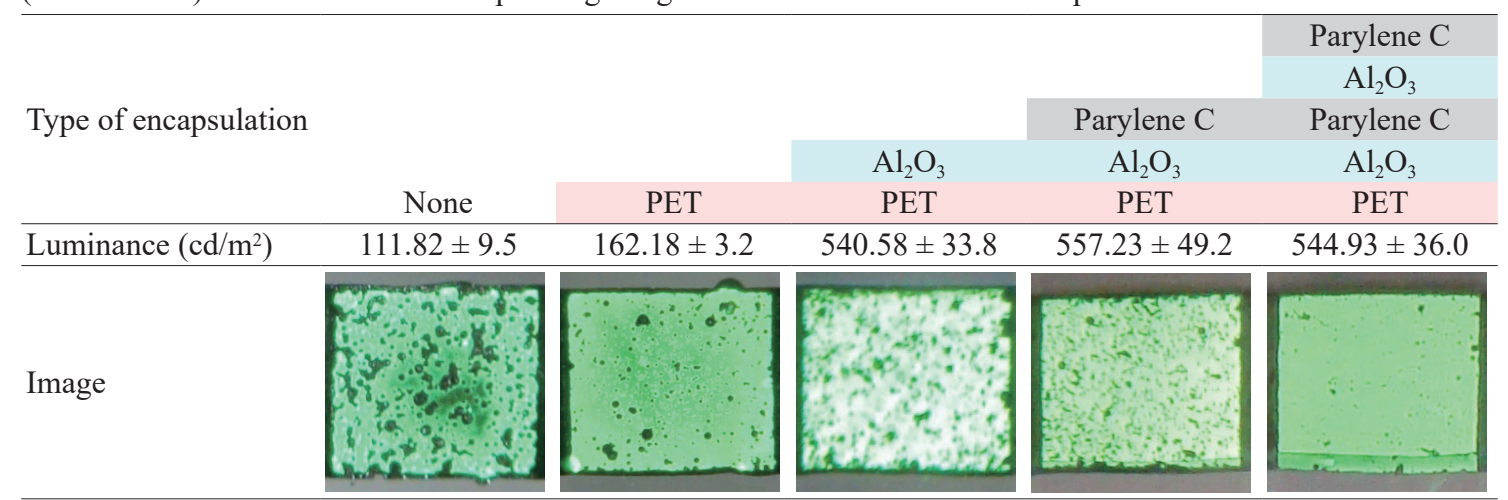




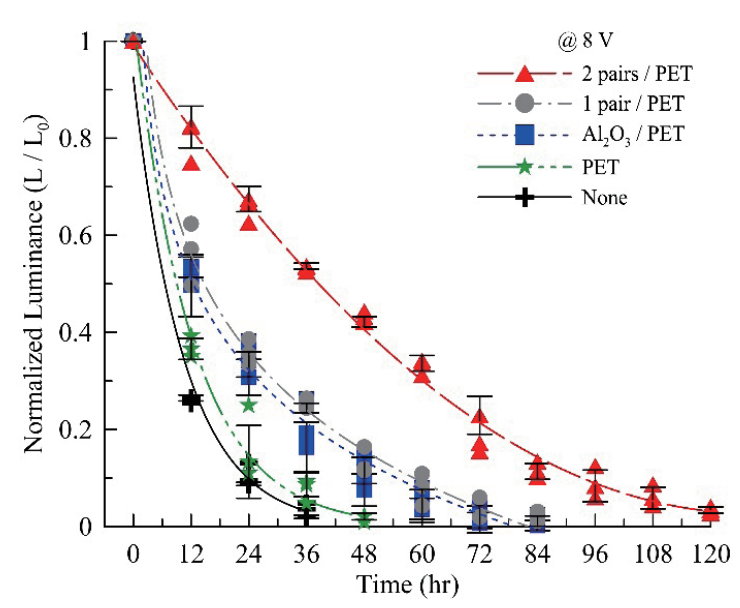

Fig. 7. (Color online) Lifetime of OLEDs with various encapsulating films.

normalized luminance was 0.26 for $12 \mathrm{~h}, 0.10$ for $24 \mathrm{~h}$, and 0.03 for $36 \mathrm{~h}$. For the OLED with PET encapsulation, the normalized luminances were $0.37,0.16,0.08$, and 0.02 for $12,24,36$, and $48 \mathrm{~h}$, respectively. The OLEDs with $\mathrm{Al}_{2} \mathrm{O}_{3} / \mathrm{PET}$ and 1 pair/PET encapsulation behave similarly with respect to lifetime. The OLED with 2 pairs/PET showed the best lifetime, where the normalized luminances were $0.80,0.66,0.53,0.43,0.33$, and 0.03 for $12,24,36,48,60$, and 120 h, respectively. Note that, although the 1 pair/PET encapsulation had slightly better luminance than the 2 pairs/PET encapsulation, the 2 pairs/PET encapsulation had a much better lifetime. The OLED with 2 pairs/PET encapsulation had nearly double the lifetime of the 1 pair encapsulation.

\section{Conclusions}

Four types of encapsulating films for flexible OLEDs were studied, and gas barrier layers including inorganic $\mathrm{Al}_{2} \mathrm{O}_{3}$ thin films prepared by ALD, organic Parylene $\mathrm{C}$ thin films prepared by chemical vapor deposition, and their combination were considered to prevent the penetration of water vapor into OLEDs. The results showed that the transmittance was acceptable even if the PET substrates were coated with two $\mathrm{Al}_{2} \mathrm{O}_{3}$ and Parylene $\mathrm{C}$ layers. The results also indicated the WVTR of the PET substrate improved if the barrier layers were coated. Comparing with the bare PET substrate, the WVTR improves 3.3 times for 1-pair coating and 4 times for 2-pairs coating. In terms of performance, the results indicate the OLED with $\mathrm{Al}_{2} \mathrm{O}_{3} / \mathrm{PET}, 1$ pair/PET, and 2 pairs/ PET have similar high luminance that is higher than the other two cases. Although the 1 pair/PET encapsulation has slightly better luminance than the 2 pairs/PET encapsulation, the 2 pairs/PET encapsulation has much longer lifetime. The OLED with 2 pairs/PET encapsulation has nearly double the lifetime compared with the 1 pair encapsulation and has a lifetime that of four times the PET without coatings.

\section{Acknowledgements}

The support from the Ministry of Science and Technology through Grant NSC 102-2221-E-129002-MY3 is gratefully acknowledged. 


\section{References}

1 A. R. Cho, E. H. Kim, S. Y. Park, and L. S. Park: Synth. Met. 193 (2014) 77.

2 L. Ke, H. Liu, M. Yang, Z. Jiao, and X. Sun: Chem. Phys. Lett. 623 (2015) 68.

3 X. Wu, J. Liu, and G. He: Org. Electron. 22 (2015) 160.

4 P. E. Burrows, V. Bulovic, S. R. Forrest, L. S. Sapochak, D. M. McCarty, and M. E. Thompson: Appl. Phys. Lett. 65 (1994) 2922.

5 J. Lewis: Mater. Today 9 (2006) 38.

6 P. F. Carcia, R. S. McLean, M. H. Reilly, M. D. Groner, and S. M. George: Appl. Phys. Lett. 89 (2006) 319151.

7 P. Mandlik, J. Gartside, L. Han, I. C. Cheng, S. Wagner, J. A. Silvernail, R. Q. Ma, M. Hack, and J. J. Brown: Appl. Phys. Lett. 92 (2008) 1033091.

8 J. H. Choi, Y. M. Kim, Y. W. Park, T. H. Park, J. W. Jeong, H. J. Choi, E. H. Song, J. W. Lee, C. H. Kim, and B. K. Ju: Nanotechnol. 21 (2010) 475203.

9 Y. C. Han, E. Kim, W. Kim, Y. G. Im, B. S. Bae, and K. C. Choi: Org. Electron. 14 (2013) 1435.

10 E. Kim, Y. C. Han, W. Kim, K. C. Choi, Y. G. Im, and B. S. Bae: Org. Electron. 14 (2013) 1737.

11 A. Singh, F. Nehm, L. Muller-Meskamp, C. Hosbach, M. Albert, U. Schroeder, K. Leo, and T. Mikolajick: Org. Electron. 15 (2014) 2587.

12 Y. Q. Yang, Y. Duan, Y. H. Duan, X. Wang, P. Chen, D. Yang, F. B. Sun, and K. W. Xue: Org. Electron. 15 (2014) 1120.

13 H. Klumbies, P. Schmidt, M. Hahnel, A. Singh, U. Schroeder, C. Richter, T. Mikolajick, C. Hosbach, M. Albert, J. W. Bartha, L. Leo, and L. Muller-Meskamp: Org. Electron. 17 (2015) 138.

14 D. Zeniieh, L. Ledernez, and G. Urban: Procedia Eng. 87 (2013) 1398.

15 X. Xie, L. Rieth, R. Caldwell, M. Diwekar, P. Tathireddy, R. Sharma, and F. Solzbacher: IEEE Trans. Biomed. Eng. 60 (2014) 2943. 